\title{
Chapter 6 \\ Bottom Turbidity, Boundary Layer Dynamics, and Associated Transport of Suspended Particulate Materials off the Fukushima Coast
}

\author{
Hiroshi Yagi, Kouichi Sugimatsu, Shigeru Kawamata, Akiyoshi Nakayama, \\ and Toru Udagawa
}

\begin{abstract}
Long-term monitoring and intensive field experiments for the bottom layer off the Fukushima coast were performed from October 2012 to November 2014 to understand the bottom processes, which are closely related to the spatial distribution and temporal variations of radiocesium in sea sediment. In this section, focusing on autumn 2012, we examine the bottom processes for a 32-m depth site (Sta. B) off Iwaki, Fukushima. Observational results showed that the bottom shear stresses from waves generally dominated over those from currents in this depth region, and the bottom turbidity increased in high wave conditions. Stepwise and significant southward cumulative transports of bottom turbidity were observed when high waves with long periods (LPW) coming from an E-ENE direction were superimposed on the southward current flow that has a periodicity of 5 days; both phenomena are influenced by successive passages of low pressure systems and the associated spatial distribution of atmospheric pressure. The combination of waves and currents caused by meteorological disturbance is a key process in the transport of suspended particulate material off the Fukushima coast.
\end{abstract}

Keywords Turbidity $\bullet$ Bottom boundary layer $\bullet$ Low period waves $\bullet$ Low pressure system

\footnotetext{
H. Yagi $(\bowtie)$

Department of Civil and Environmental Engineering, National Defense Academy,

1-10-20, Hashirimizu, Yokosuka, Kanagawa 239-8686, Japan

e-mail: yagih@nda.ac.jp

K. Sugimatsu $\bullet$ S. Kawamata $\bullet$ A. Nakayama $\bullet$ T. Udagawa

National Research Institute of Fisheries Engineering, Fisheries Research Agency,

7620-7, Hasaki, Kamisu, Ibaraki 314-0408, Japan
} 


\subsection{Introduction}

More than 3 years have passed since the accident at the Fukushima Dai-ichi Nuclear Power Plant (FNPP) associated with the Great Earthquake east of Japan on March 11, 2011. Concentrations of seawater radionuclides are decreasing, but the bottom sediment still has appreciable levels of radionuclides that could be incorporated in the benthic ecosystem. Therefore, it is important to understand the details of the spatial distribution and temporal variations of radionuclide concentrations included in the bottom sediment. Several studies have investigated the spatial distribution of radiocesium in the seabed (Otosaka and Kobayashi 2013; Kusakabe et al. 2013; Thornton et al. 2013; Ambe et al 2014); however, to understand the formation mechanism of the measured spatial distributions and temporal variations of sea bottom radiocesium, the characteristics of suspended sediment transport in the Fukushima coastal sea area must be known. These characteristics are closely related to the movement of sediment and suspended particulate radiocesium. In this section, we introduce the characteristics of bottom turbidity, boundary layer dynamics, and associated bottom turbidity transport off the Fukushima coast, based on the field measurement results reported by Yagi et al. (2013).

\subsection{Outline of Field Measurements for Bottom Processes off the Fukushima Coast}

We performed two kinds of field measurements to understand the bottom processes off the Fukushima coast: one was the long-term monitoring of coastal bottom environments focusing on basic parameters (current, wave, turbidity, temperature, salinity), and the other was an intensive field survey aimed at understanding the details of bottom boundary layer dynamics and associated sediment transport processes. For long-term monitoring, three monitoring sites were deployed off Iwaki, the southern part of the Fukushima coast (stations B, C, and D at depths of 32, 80, and $130 \mathrm{~m}$, respectively), and one site (Sta. A at a depth of $30 \mathrm{~m}$ ) off Ooarai on the Ibaraki coast (see Fig. 6.1). Bottom-mounted and bottom-moored instrument platforms were installed with an ADCP (acoustic Doppler current profiler, Telendy RDI), OBS (optical back-scatter sensor for turbidity, Infinity-CLW, JEF-advantec), and salinity-temperature sensors (Infinity-CTW, JEF-advantec) (Fig. 6.2a); mooring systems to measure the surface and middle layer conditions (temperature, salinity, and turbidity) were also deployed for stations A and B. Measurements began in mid-October 2012 and continued for 2 years until early November 2014. The intensive survey focusing on the bottom boundary layer involved the installation of a bottom tripod (Fig. 6.2b) equipped with a vertical array of OBSs, a 3-D acoustic Doppler velocimeter (ADV-Vector, Nortec), and an in-situ laser particle size analyzer (LISST-100x, Sequoia Sci) at Sta. B (32 m depth) (Fig. 6.1). Three field campaigns were conducted: BBL-Exp. I (15 October to 20 November 2012), BBL-Exp. II (13 February to 25 March 2013), and BBL-Exp. III (1 November to 15 December 2013). 

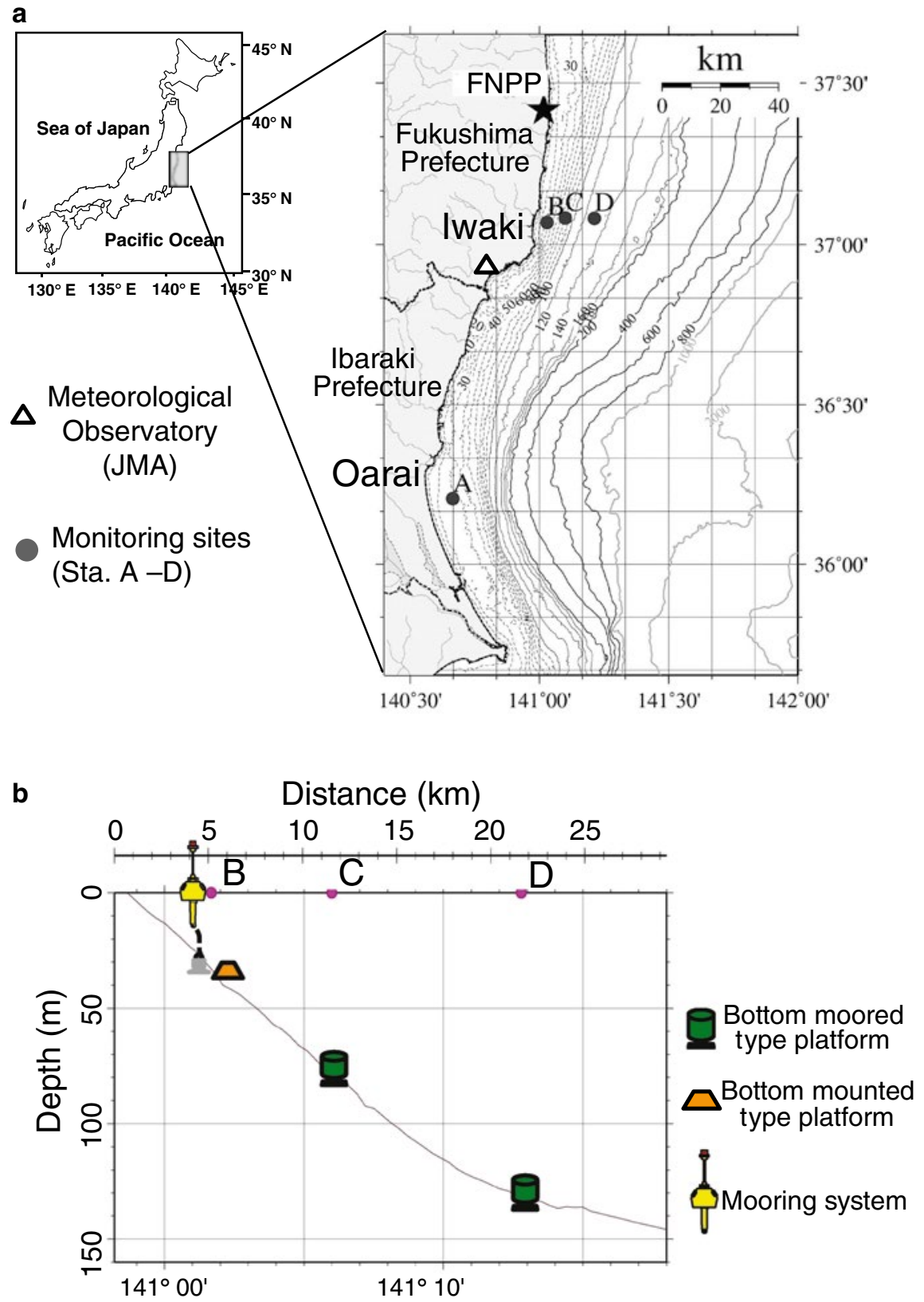

Fig. 6.1 (a) Map of study area. Topography and locations of monitoring station A off Oarai of Ibaraki Prefecture, and stations B, C, and D off Iwaki of Fukushima Prefecture. FNPP marks the location of the Fukushima Dai-ichi Nuclear Power Plant. (b) On- to offshore topography changes around the monitoring sites off Iwaki and locations of stations B, C, and D 
a

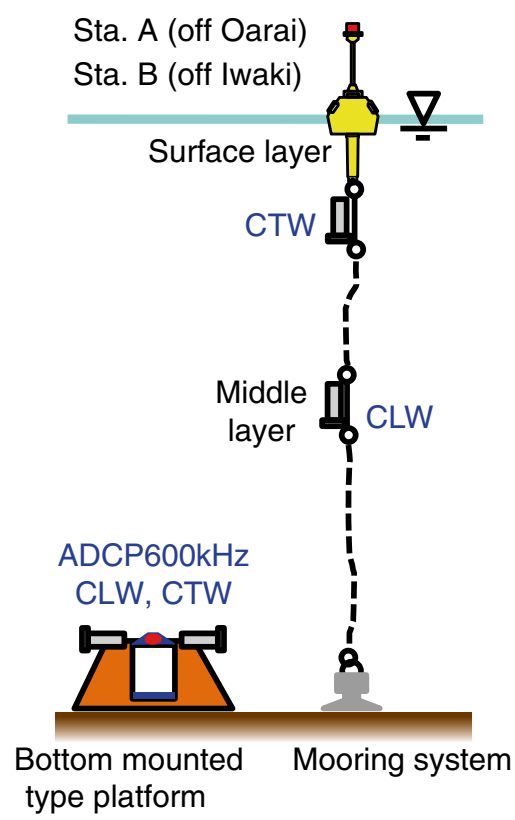

Sta. C, D (off Iwaki)

$\underline{\nabla}$

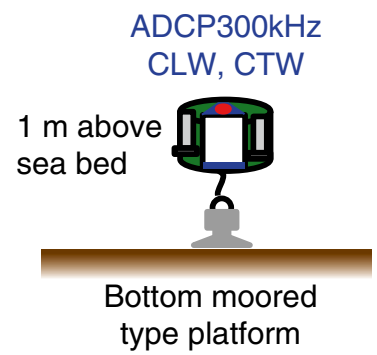

b

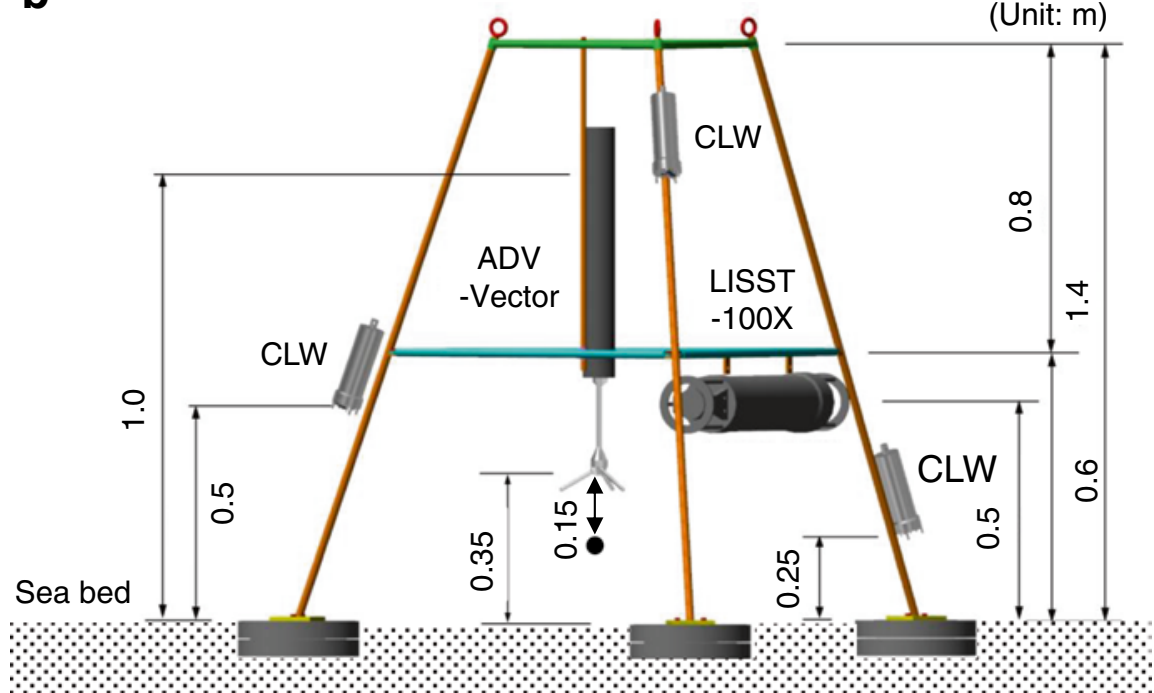

Fig. 6.2 Schematics of the monitoring systems. (a) Deployed experimental setup of the instrument platform (bottom-mounted and -moored types) and mooring system at stations A-D. (b) Bottom tripod for bottom boundary layer experiment and instrumentation layout. CLW shows OBS (optical back-scatter sensor for turbidity) and CTW shows a salinity-temperature sensor 
Of all the data from these measurements, we focused first on the bottom boundary layer experiment for the 32-m depth site (Sta. B) and the corresponding long-term monitoring in autumn 2011. The fundamental characteristics of bottom processes off the Fukushima coast for this period are discussed in the following subsections.

\subsection{Bottom Turbidities and Boundary Layer Characteristics off the Fukushima Coast in Autumn 2012}

Measurement results in autumn 2012 revealed that temporal variations in turbidity in the inner-shelf and mid-shelf bottom layers off the Fukushima coast have different characteristics (Fig. 6.3). The bottom turbidities at the inner-shelf site
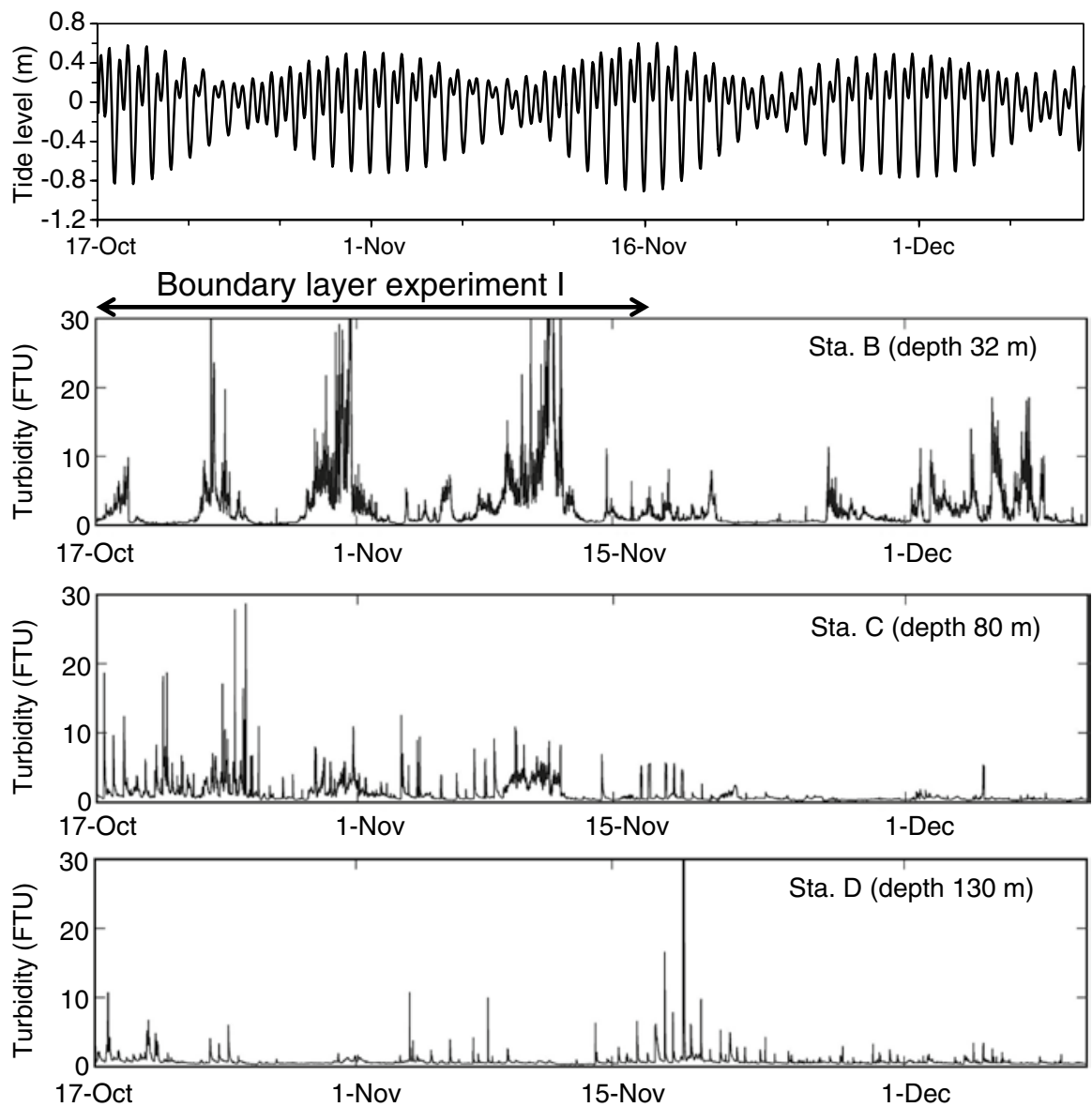

Fig. 6.3 Bottom turbidities at stations B, C, and D with tidal elevations in autumn 2012. The turbidity data are given in FTUs (Formazin turbidity units) 
a

Bottom currents $\mathrm{U}_{\mathrm{C}}$

North - Atmospheric pressure $\mathrm{P} \quad$ - - - Moving average of $U_{C}$

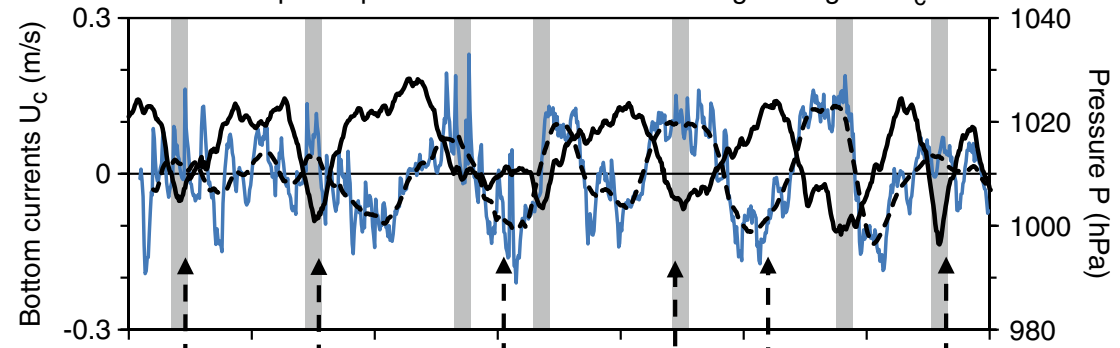

South 16-Oct 21-Oct 26-Oct 31-bct 5-Nov i 10-Nbv $15-\mathrm{Nov}$ I
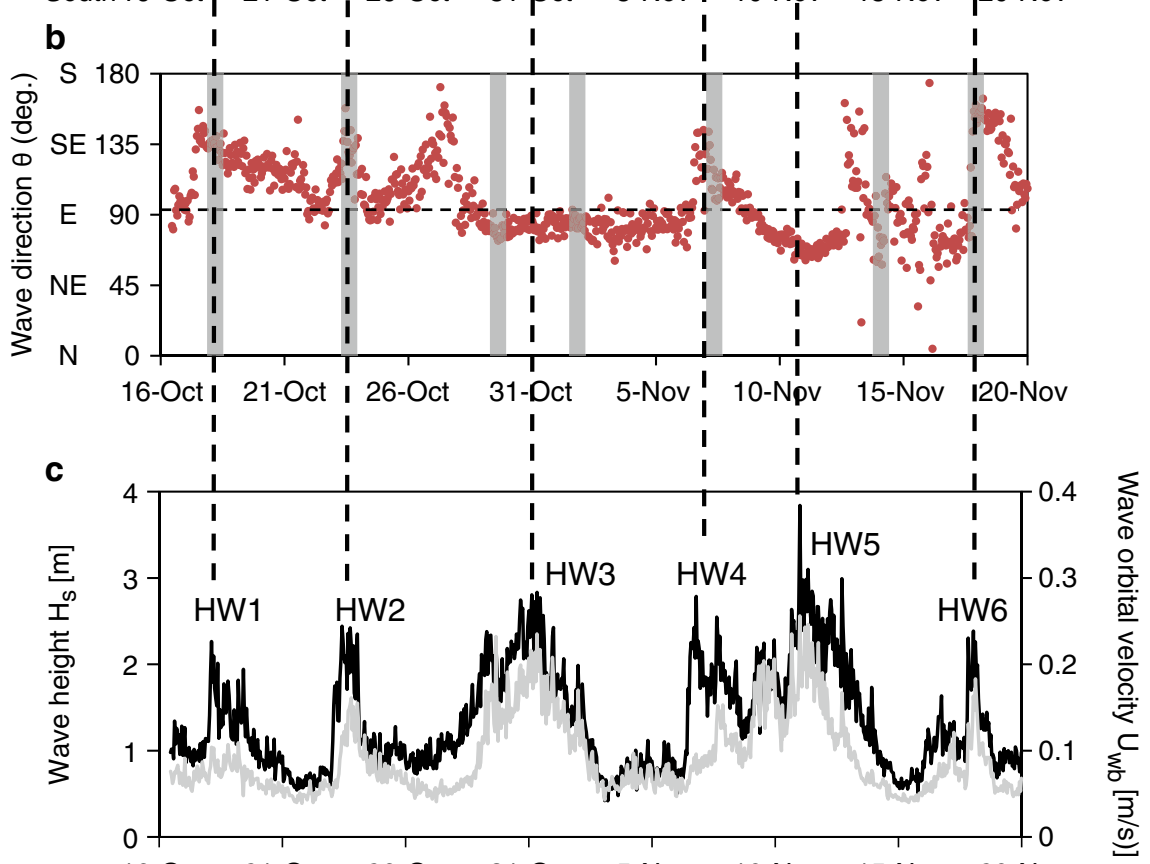

16-Oct 21-Oct 26-Oct 31-Oct 5-Nov 10-Nov 15-Nov 20-Nov

d

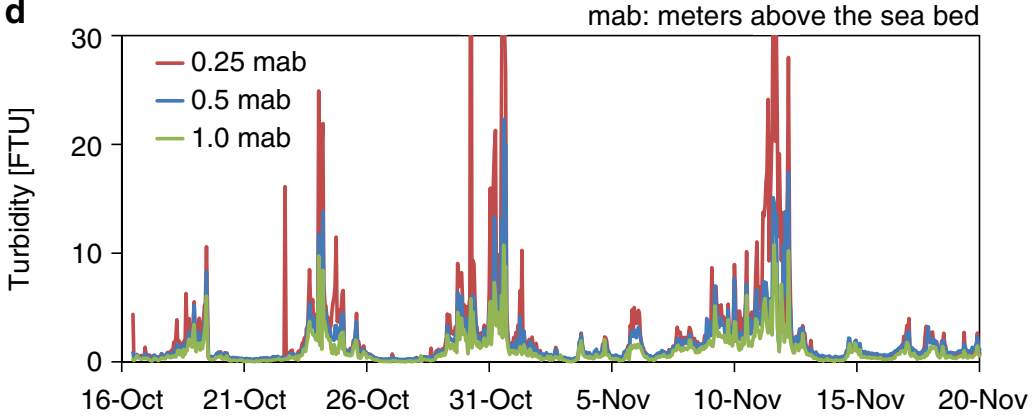

Fig. 6.4 Measurement results for the bottom boundary experiment: bottom currents and atmospheric pressure (a), wave direction (b), significant wave heights $\left(\mathrm{H}_{\mathrm{s}}\right.$, black trace) and wave orbital 
(32-m depth; Sta. B) were generally larger than those at the mid-shelf site (130-m depth; Sta. D), and Sta. B saw high turbidity conditions over several days. In contrast, turbidity at the mid-shelf site (Sta. D) showed temporal variations with high frequencies. The intermediate depth site (80-m depth; Sta. C) combined the bottom turbidity features observed at the inner- and mid-shelf sites.

Focusing on the inner-shelf bottom layer, we examined the details of boundary layer characteristics (currents, waves, bottom shear stress) and the relationships with bottom turbidities (Fig. 6.4). The bottom currents (Fig. 6.4a) showed temporal variations with a period of around 5 days, which were well correlated with low pressure system passages over the study area (shown by the gray hatching in this figure) associated with temporal variations of local atmospheric pressure. These periodic and subtidal current fluctuations off the Fukushima coast were also observed by Kubota et al. (1981) and were thought to be shelf waves in the forcing region caused by periodic meteorological disturbances (Kubota 1982). In contrast, waves observed in high wave conditions showed two distinct sets of characteristics. (1) High waves during low pressure passages had relatively shorter wave periods and an ESE-SSE wave direction (type 1: corresponding to the high wave periods HW1, HW2, HW4, and HW6 in Fig. 6.4c, and indicated as type 1 in Fig. 6.5a). (2) High waves occurring in the intervals between low pressure passages had longer wave periods and an E-ENE wave direction (type 2: corresponding to the high wave periods HW3 and HW5 in Fig. 6.4c, and indicated as type 2 in Fig. 6.5a). These different characteristics were the result of the different wave generation systems, in that type 1 was induced by the passage of a low pressure system over the study area (Fig. 6.5b, left panel) and type 2 developed off the east part of the main island of Japan (Fig. 6.5b, right panel) and propagated into the study region from an E-ENE direction with longer periods.

Bottom shear stress from currents and waves $\left(\tau_{c}\right.$ and $\left.\tau_{w}\right)$ can be evaluated by the following equations (Soulsby 1997):

$$
\begin{gathered}
\tau_{c}=\rho U_{c}^{2} /\left[\frac{1}{\kappa} \ln \left(\frac{z}{z_{0}}\right)\right]^{2} \text { and } \\
\tau_{w}=\rho \frac{1}{2} f_{w} U_{w}^{2},
\end{gathered}
$$

where $U_{c}$ is the current velocity at $z$ (elevation above the sea bed), $\kappa$ is the von Karman constant, $\rho$ is the density of seawater, $z_{0}$ is the bed roughness length, $U_{w}$ is

Fig. 6.4 (continued) velocities $\left(U_{\mathrm{wb}}\right.$, gray trace) $(\mathbf{c})$, and turbidities $(\mathbf{d})$ at $0.25,0.5$, and $1 \mathrm{~m}$ above the seabed. Timing of low pressure passages over the study area, which were defined from local atmospheric pressure data and synoptic-scale information on atmospheric pressure (weather map) from the JMA (Japan Meteorological Agency), is shown by the gray hatching in (a) and (b). (c) HW 1-6 are high wave periods during the observation period. HW1, $-2,-4$, and -6 occurred during the low pressure passage; HW3 and -5 in intervals between low pressure passages are shown by dotted arrows 
a

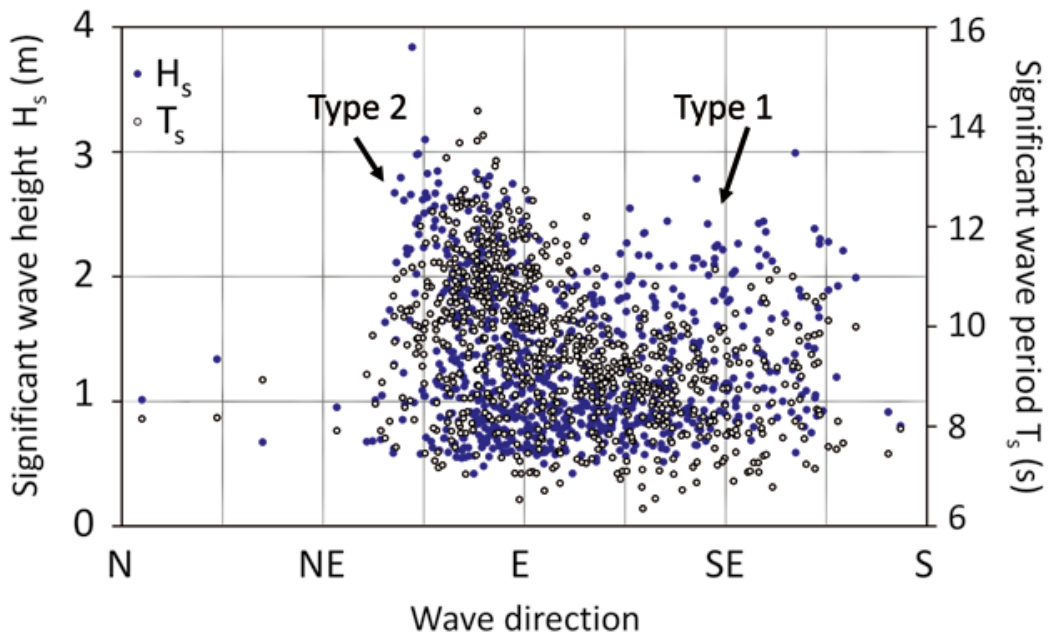

b

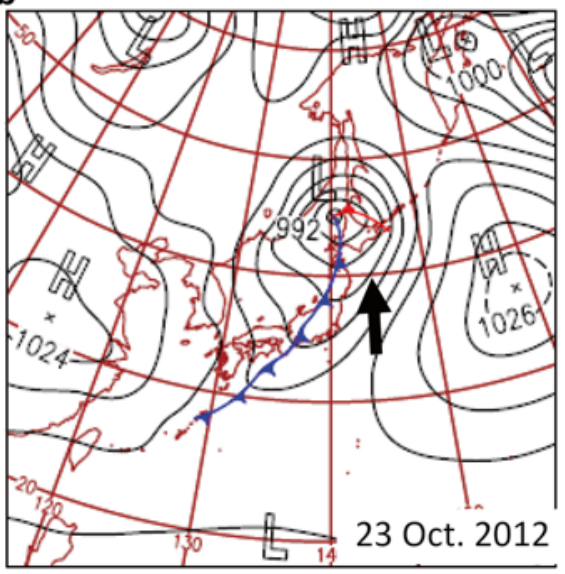

High wave period HW2

(Type 1: high waves that occurred during low pressure passages)

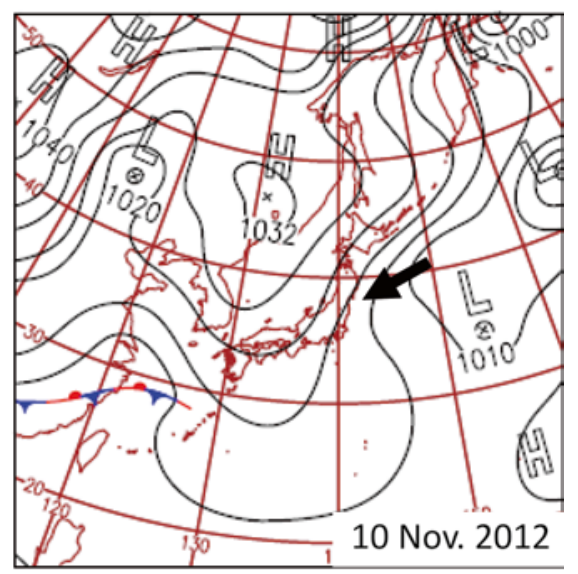

High wave period HW5

(Type 2: high waves that occurred in the intervals between low pressure passages)

Fig. 6.5 (a) Relationship between wave direction, significant wave heights, and wave periods for autumn 2012. (b) Weather map by the JMA for two high wave periods: left, high wave period HW2 (type 1); right, high wave period HW5 (type 2). Wave directions are illustrated based on the wave map by the JMA

the bottom wave orbital velocity, and $f_{w}$ is the bottom friction coefficient caused by waves (Soulsby 1997). By substituting the measured ADCP velocity at the lowest layer $(z=2.12 \mathrm{~m})$ for $U_{c}$, and RMS wave orbital velocities by the ADV-Vector for $U_{w}$, we can obtain the bottom shear stresses.

The estimated bottom shear stress caused by waves $\left(\tau_{w}\right)$ generally dominated over that caused by currents $\left(\tau_{c}\right)$ in autumn 2012 and showed larger values in type 2 high wave conditions (HW3 and HW5 in Fig. 6.6a). Furthermore, $\tau_{w}$ correlates well 

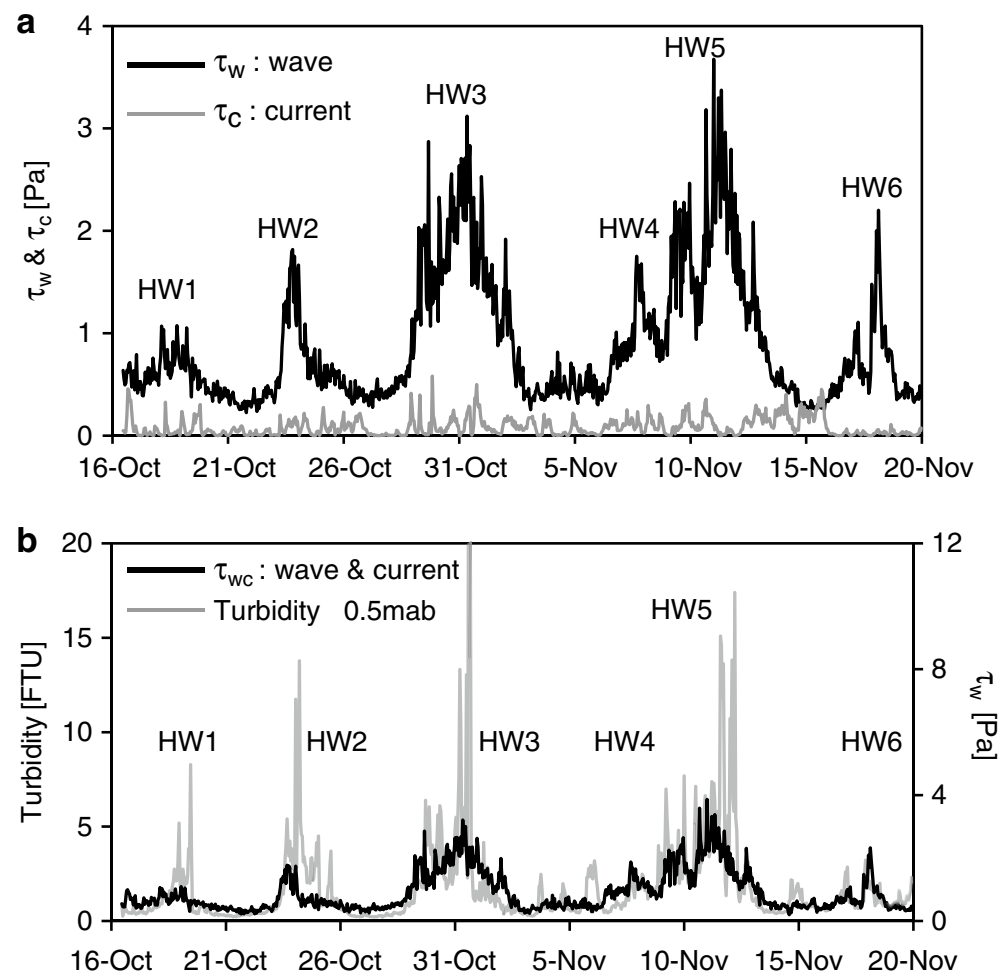

Fig. 6.6 (a) Temporal variations in estimated bottom shear stresses caused by waves $\left(\tau_{w}\right)$ and currents $\left(\tau_{c}\right)$. (b) Temporal variations in bottom turbidities $(0.5 \mathrm{mab})$ and $\tau_{w}$ for autumn 2012. HW $1-6$ in the figure are as defined for Fig. $6.4 \mathrm{c}$

with the observed turbidities, meaning high turbidity conditions occurred simultaneously with the larger bottom shear stresses (Fig. 6.6b). These observational results demonstrate that the larger bottom turbidities are induced by the high wave conditions in the intervals between low pressure passages (type 2), which showed longer wave periods and larger bottom shear stresses.

\subsection{Near-Bottom Turbidity Transport off Fukushima Coast Under the Condition of Successive Low Pressure Passages}

To understand the characteristics of near-bottom turbidity transport off the Fukushima coast, which are closely related to the movement of suspended sediment and particulate radiocesium, we evaluated the turbidity transport rates from the estimated vertical distributions of turbidity and velocity in the bottom layer. Measured 
bottom turbidities at three different depths $(0.25,0.5$, and $1 \mathrm{~m}$ above the seabed) were approximated with the exponential function

$$
C(z)=C_{\mathrm{be}} \cdot \exp [-\alpha \cdot z]
$$

where $C(z)$ is estimated turbidity and $z$ is the distance above the seabed. $C_{\mathrm{be}}$ (reference bottom turbidity) and $\alpha$ (shape factor) are time-varying parameters decided by regression analysis of the measured bottom turbidities. Additionally, the vertical profile of bottom current velocities can be approximated using a well-known logarithmic law of the wall for a sea bottom boundary layer (Soulsby 1997) as follows:

$$
u(z)=\frac{\ln z-\ln z_{0}}{\ln z_{\mathrm{ADCP}}-\ln z_{0}} u_{\mathrm{ADCP}}
$$

where $u(z)$ is estimated bottom velocity (north-south or east-west component), $u_{\mathrm{ADCP}}$ is the velocity of the lowest layer of ADCP (north-south or east-west component), and $z_{\mathrm{ADCP}}$ is the distance above the seabed for the lowest layer of ADCP ( $2.12 \mathrm{~m}$ above the seabed). Horizontal turbidity flux is calculated as the product of Eqs. (6.3) and (6.4) and integrated over the bottom layer to evaluate the bottom turbidity transport rate $q_{b}$ as follows:

$$
q_{b}=\int_{0}^{z_{b}} C(z) \cdot u(z) \cdot d z
$$

where $z_{b}$ is the thickness of the bottom layer. defined here as $2 \mathrm{~m}$.

The estimated temporal and vertical distribution of bottom turbidity (Fig. 6.7a) shows that significant turbidity variation occurred predominantly below $2 \mathrm{~m}$ above the seabed in autumn 2012. The cumulative transport rate $q_{b}$ (Fig. 6.7b) demonstrates that southward transport dominated and occurred stepwise during type 2 high wave periods (HW3 and HW5 in Fig. 6.7b), which have longer wave periods and larger bottom shear stresses, as shown in Figs. 6.5a and 6.6a. In contrast, as discussed, the bottom currents represent temporal variations with a periodicity around 5 days, and southward currents occurred in the intervals between low pressure atmospheric events. As a result, significant southward bottom turbidity transport was induced during high wave periods HW3 and HW5 (Fig. 6.7b), in the interval between low pressure events when higher bottom turbidities and southward bottom currents co-occurred. From these observational results, it is revealed that successive low pressure passages and the associated spatial distributions of atmospheric pressure influenced both the current and wave fields, and that significant southward bottom turbidity transports were induced by the co-occurrence of high waves coming from E-ENE with longer periods (favorable for high bottom turbidity) and southward bottom currents in the interval between low pressure passages (Fig. 6.8). The relationship between waves and currents through atmospheric conditions is an important influence on bottom processes off the Fukushima coast. 
a

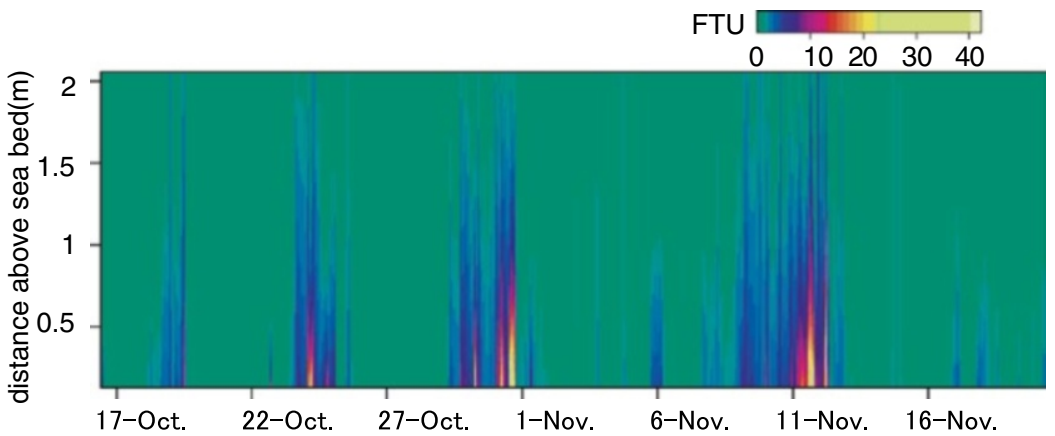

b

North

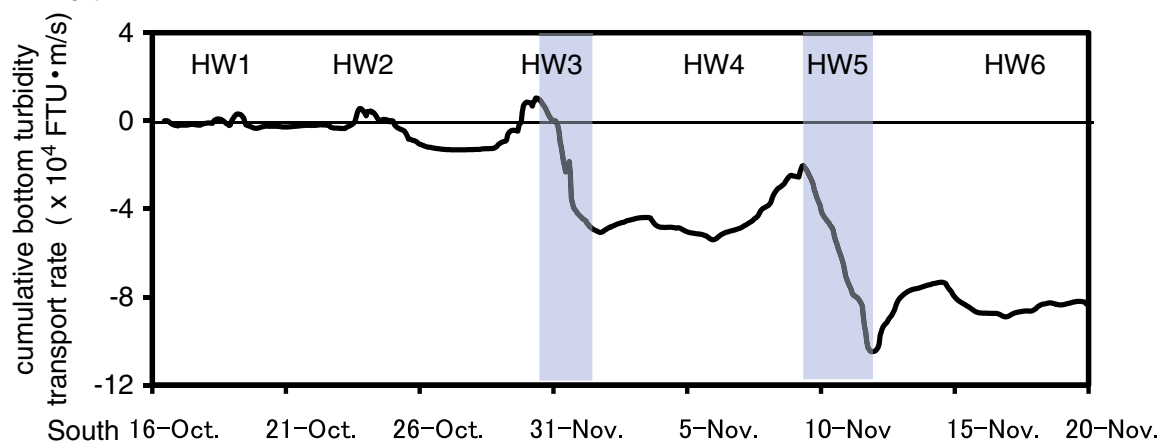

Fig. 6.7 (a) Temporal and vertical distribution of turbidity estimated by Eq. (6.3). (b) Temporal variation of the cumulative value of the bottom turbidity transport rate found by Eq. (6.5) (northsouth direction). HW1-6 in $\mathbf{b}$ as defined for Fig. $6.4 \mathrm{c}$

In the bottom boundary layer experiment in autumn 2012, a sediment trap was also installed at the inner-shelf site (32-m depth, Sta. B) to measure the sinking flux and radiocesium concentration of suspended particulate material in the bottom layer (Kaeriyama et al. 2013). The measurement results showed a significant correlation between bottom turbidities and the sinking fluxes of particulate radiocesium (Yagi et al. 2014), which fact suggests that sediment or particulate radiocesium movements are closely related to the transport processes of the bottom turbidity examined here.

\subsection{Conclusions}

In this section, fundamental characteristics of bottom turbidity, bottom boundary layer dynamics, and associated bottom turbidity transport off the Fukushima coast were examined based on field measurement results in autumn 2012, focusing on the inner-shelf bottom layer (32-m depth, Sta. B). Observational results showed that the bottom shear stresses from waves generally dominated those caused by currents, and the bottom turbidity increased in high wave conditions. In particular, significant 
During low pressure passage

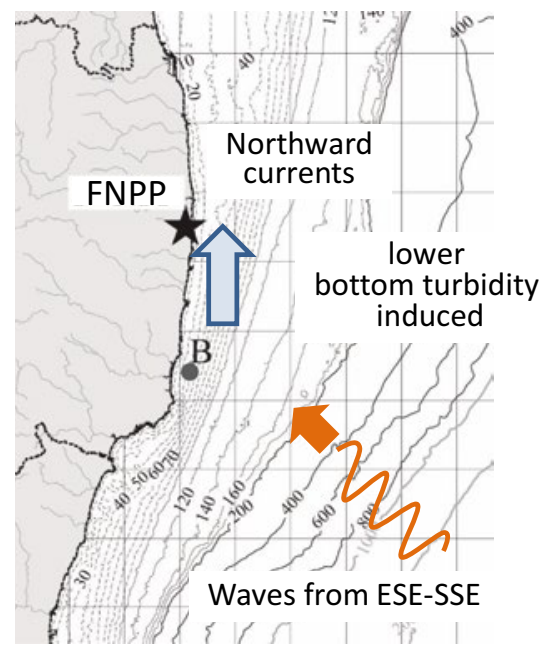

High wave Type 1

(Periods: HW1, 2, 4, and 6)
Interval between low pressure passages

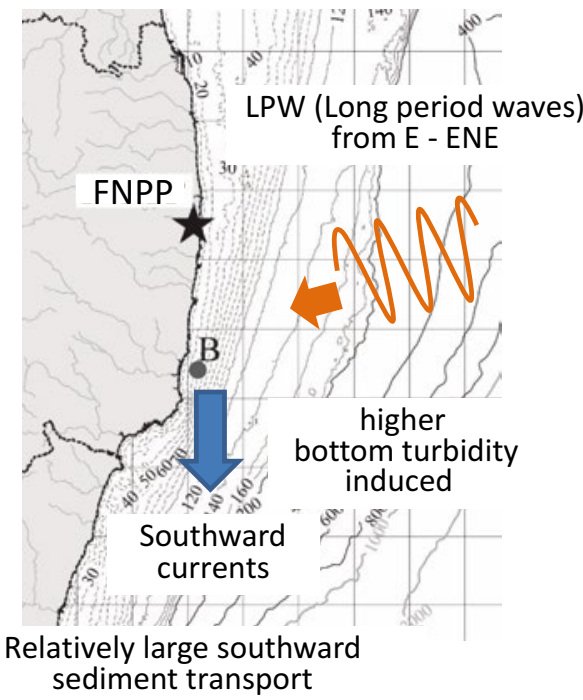

High wave Type 2

(Periods: HW3 and 5)

Fig. 6.8 Schematic illustrations of bottom turbidity transport processes for type 1 and type 2 high wave events

and stepwise southward cumulative transport of bottom turbidity was observed when southward currents and high waves coming from an E-ENE direction with longer periods co-occurred. This combination of bottom current variations with a periodicity of several days and high wave conditions with longer wave periods (LPW), both of which are influenced by the successive passage of periodic low pressure systems and the associated spatial distribution of atmospheric pressure, affects the transport of suspended particulate material in the bottom layer. The results of this study highlight the importance of the relationship between atmospheric conditions and trends in waves and currents in understanding the bottom processes off the Fukushima coast.

Acknowledgments We appreciate the extensive support from Mr. A. Suzuki, Mr. M. Hosono, and Mr. M. Kobayashi of International Meteorological \& Oceanographic Consultants Co. Ltd, and from Mr. Y. Nishi of Alpha Hydraulic Engineering Consultants Co., Ltd. This study was financially supported by the Fisheries Research Agency of Japan.

Open Access This chapter is distributed under the terms of the Creative Commons Attribution Noncommercial License, which permits any noncommercial use, distribution, and reproduction in any medium, provided the original author(s) and source are credited. 


\section{References}

Ambe D, Kaeriyama H, Shigenobu Y, Fujimono K, Ono T, Sawada H, Saito H, Miki S, Setou T, Morita T, Watanabe T (2014) A high-resolved spatial distribution of radiocesium in sea sediment derived from Fukushima Dai-ichi nuclear power plant. J Environ Radioact 136:218-228

Kaeriyama H, Ambe D, Ono T, Yagi H, Sugimatsu K, Kawamata S, Udagawa T, Nakayama T, Watanabe T (2013) Sinking flux of particle radioactive cesium near sea bottom off the coast of Fukushima prefecture. In: Fall Meeting of the Oceanographic Society of Japan, Sapporo, Hokkaido, Japan, 17-21 Sept 2013, 316, p. 162 (in Japanese)

Kubota M (1982) Continental shelf waves off the Fukushima coast. Part II: theory of their generation. J Oceanogr Soc Jpn 38:323-330

Kubota M, Nakata K, Nakamura Y (1981) Continental shelf waves off the Fukushima coast. Part I: observations. J Oceanogr Soc Jpn 37:267-278

Kusakabe M, Oikawa S, Takata H, Misonoo J (2013) Spatiotemporal distributions of Fukushimaderived radionuclides in nearby marine surface sediments. Biogeosciences 10:5019-5030

Otosaka S, Kobayashi T (2013) Sedimentation and remobilization of radiocesium in the coastal area of Ibaraki, $70 \mathrm{~km}$ south of the Fukushima Dai-ichi Nuclear Power Plant. Environ Monit Assess 185(7):5419-5433

Soulsby R (1997) Dynamics of marine sands. Thomas Telford, London, p 249

Thornton B, Ohnishi S, Ura T, Odano N, Fujita T (2013) Continuous measurement of radionuclide distribution off Fukushima using a towed sea-bed gamma ray spectrometer. Deep-Sea Res I 79:10-19

Yagi H, Sugimatsu K, Nishi Y, Kawamata S, Nakayama A, Udagawa T, Suzuki A (2013) Field measurements of bottom boundary layer and suspend particle materials on Jyoban coast in Japan. Journal of Japan Society of Civil Engineers, Ser B2 (Coastal Engineering) 69(2): 1046-1050 (in Japanese)

Yagi H, Sugimatsu K, Kawamata S, Nakayama A, Udagawa T, Kaeriyama H, Ono T, Ambe D (2014) Estimation of horizontal flux of particulate radiocesium in the bottom layer off Joban coast. In: Spring Meeting of the Oceanographic Society of Japan, Tokyo, Japan, 26-30 March 2014, 201, p. 59 (in Japanese) 